\title{
LA PEDAGOGíA WALDORF Y EL JUEGO En EL JARDÍ́ DE InFAnCIA. UnA PROPUESTA TEÓRICA SIIIUULAR
}

\author{
Waldorf Education and Play in the Kindergarden. An \\ Outstanding Theoretical Proposal
}

PATRICIA QUIROGA UCEDA

Universidad Complutense

JON IGELMO ZALDÍVAR

Universidad de Deusto

En este artículo se presenta un análisis teórico de la concepción del juego en las escuelas Waldorf. Se pone especial énfasis en el caso de la educación infantil y su relación con la actividad lúdica. Con el fin de abarcar un análisis de estas características, este trabajo se inicia con un acercamiento esquemático tanto a la figura del considerado ideólogo de esta singular alternativa educativa, Rudolf Steiner, como a los principios teóricos más destacados de la pedagogía Waldorf. Para este estudio se toma como referencia una perspectiva historiográfica crítica en clara sintonía con las corrientes contemporáneas del campo de la historia de la ideas. La aportación fundamental de este trabajo se centra en detectar seis características que definen desde una perspectiva teórica el juego para la educación de naturaleza antroposófica. Estas características del juego en el jardín de infancia Waldorf son: su capacidad de contribución en la consolidación de ciertos hitos evolutivos, la vinculación que presenta con la naturaleza imitativa del niño, su ubicación en momentos que favorecen la respiración; la utilización de objetos hechos con materiales naturales y versátiles; la exclusión de elementos intelectuales de sus objetivos; y, por último, su vinculación con el desarrollo espiritual de los niños. Todo lo cual lleva a concluir con la principal novedad que aporta la pedagogía Waldorf al debate en torno al juego, la infancia y la educación, esto es, la necesidad que este movimiento pedagógico reivindica de integrar la educación al juego y nunca al contrario.

Palabras clave: Juego, Pedagogía Waldorf, Antroposofia, Rudolf Steiner, Espiritualidad.

«Aquí se aprende muy poco, falta personal docente y nosotros, los muchachos del instituto Benjamenta, jamás llegaremos a nada, es decir el día mañana seremos todos gente muy modesta y subordinanda.»

Robert Walser, Jakob Von Gunten, p. 9

\section{Introducción}

Entrado el siglo XXI es complicado concebir una corriente de pensamiento dentro de la pedagogía que no desarrolle una mínima perspectiva teórica del juego. Asimismo, sería un

Fecha de recepción: 3-5-12 - Fecha de aceptación: 18-6-12

Bordón 65 (I), 2013, 79-92, 15SN: 0210-5934 • 79 
ejercicio arriesgado, por lo menos en el mundo occidental, desvincular del juego el periodo de tiempo que culturalmente se asocia con la infancia. Todo indica que juego, infancia y educación son términos condenados a entenderse.

Con todo, es posible percibir en la pedagogía desarrollada tanto por vanguardias progresistas como por corrientes más conservadoras, una tendencia predominante por integrar en la educación el juego y la infancia. La discusión, hasta el momento, se ha centrado en dilucidar en qué medida el juego debe tener protagonismo dentro del proceso educativo correspondiente a la infancia; qué tipo de actividades, materiales, tiempos o espacios lúdicos son más adecuados para una determinada edad; o cuál es el rol que corresponde al docente como responsable último de la organización del tiempo de juego dentro de una escuela infantil. Bien podría decirse que todavía la comunidad científica internacional de la pedagogía, en buena medida, no se ha alejado en lo sustancial del camino que fue trazado por la generación de autores que lideraron el movimiento de la Escuela Nueva a principios del siglo XX.

En consecuencia, lo que se plantea en este trabajo, esto es, indagar en el pensamiento que Rudolf Steiner desarrolló en relación al juego, la infancia y la educación, se asemeja en buen grado a un ejercicio de remar contracorriente. Baste mencionar que Steiner, al plantear los fundamentos teóricos de la pedagogía antroposófica en las primeras décadas del siglo XX, apenas consideró relevante dar continuidad a la tendencia predominante del pensamiento educativo de esta época. Por el contrario, adoptó una postura transgresora y sui géneris que le llevó a repensar no solo las nociones de educación, juego e infancia, sino también el ser humano en su totalidad, incluyendo su pasado, su presente y su futuro.

Es cierto que Steiner y su propuesta pedagógica con demasiada frecuencia han sido clasificados de excéntricos, sectarios y elitistas, y que en la mayoría de los casos el impacto del trabajo desarrollado en las escuelas Waldorf ha sido marginal. Sin embargo, a la sombra de los síntomas de las crisis económica, medioambiental, política, cultural y educativa que hoy experimenta occidente, quizá sea el momento de poner más atención precisamente en aquellas propuestas que desde su aparición han denunciado muchas de las consecuencias que se podían derivar de un modelo de convivencia que en la actualidad se muestra decadente y caduco.

Y es esta la atención que merecen alternativas pedagógicas como la desarrollada por la antroposofía, que desde una perspectiva académica encuentra su valor intrínseco no tanto en la exploración de nuevas fórmulas que permitan dotar de más recursos y tecnología al juego, más espacios físicos para la infancia o más personal dedicado a la educación, sino en una metodología que aporte una nueva definición del juego. Una metodología que reubique el periodo de tiempo de la infancia y lo relacione, también, con otras etapas evolutivas de los seres humanos. Un método que en vez de buscar compulsivamente como encajar el juego dentro del proceso educativo, busque el lugar que corresponde a la educación dentro de la actividad natural del ser humano, que no es otra, según Steiner, que el propio juego. Y es aquí donde reside el interés de un trabajo como el que a continuación se presenta, cuya intención es plantear un acercamiento, sin duda limitado por razones de espacio, a la pedagogía Waldorf y la propuesta teórica singular del juego que presenta en el jardín de infancia.

Este es un texto que retoma en buena medida el pensamiento de un autor como Steiner y que encuentra, a su vez, fundamento en la teoría y la historia de la educación. Metodológicamente recoge la crítica planteada por los historiadores de las ideas (Cabrera Acosta, 2005). Sucede que estas corrientes historiográficas lejos de apostar por dar continuidad a nuevos estudios que buscan aproximarse a lo que realmente quería decir un pensador sobre un determinado tema 
La pedagogía Waldorf y el juego en el jardín de infancia. Una propuesta teórica singular

o al modo en que ideas planteadas hace tiempo pueden ayudar a resolver problemas actuales, exploran el pensamiento de un autor con la intención de abrir nuevos interrogantes sobre una realidad aparentemente dada (Rorty, 1990). Y tal es el objetivo que recorre este artículo, esto es: abrir nuevos interrogantes sobre el juego, la infancia y la educación a partir del pensamiento de un autor como Steiner que nació hace más de 150 años y que es considerado, al inicio del siglo XXI, padre intelectual de la pedagogía antroposófica y de las escuelas Waldorf.

\section{Rudolf Steiner y el origen de la pedagogía Waldorf}

La pedagogía Waldorf, cuya primera escuela se abrió en septiembre de 1919 en Stuttgart (Alemania), nace de la antroposofía, un movimiento de renovación espiritual creado por Rudolf Steiner en Europa durante la primera década del siglo XX.

Nacido en la ciudad croata de Donji Kraljevec el 25 de febrero 1861, Rudolf Steiner realizó sus estudios escolares y universitarios en el ámbito científico, los cuales complementó desde una temprana edad con una formación autodidacta en filosofía, literatura e historia. Estos aprendizajes serían la base para el posterior desarrollo de su tarea profesional que abarcaría un amplio abanico de disciplinas como las artes, la agricultura, la medicina, la filosofía, la renovación social, la economía y la educación. Todas ellas desde su particular visión esotérica del ser humano y del mundo.

Según narra el propio Steiner en su autobiografía el primer momento en el que percibió cierta concepción espiritual de la existencia humana estuvo relacionado con un acercamiento a la geometría. Tenía entonces nueve años. Estas tempranas experiencias espirituales le llevaron a afirmar ya en el final de su vida: «La realidad del mundo espiritual era para mí tan segura como la del mundo sensorio [...]. Distinguía cosas y entidades ‘que se ven' y otras 'que no se ven'» (Steiner, 1997: 18). Para Steiner las percepciones que se encuentran fuera del alcance de los sentidos, es decir, del mundo suprasensible, existían en la cotidianidad despertando «preguntas indefinidas acerca del mundo y de la vida» (Steiner, 1997: 25). Por eso, a medida que fue avanzando en los cursos escolares durante su adolescencia, las distintas materias le fueron ofreciendo estímulos y caminos por los que transitar en la búsqueda de respuestas. Pero no fue hasta su ingreso en la Escuela Superior Técnica cuando dirigió sus pasos hacia un objetivo que sería la base de su pensamiento, en palabras del propio Steiner: «Poder expresar mis videncias directas del mundo espiritual en forma de pensamientos» (1997: 38).

Al finalizar sus primeros estudios, la vida profesional de Steiner tuvo continuidad en nuevos espacios académicos, como el archivo de Goethe-Schiller en Weimar (Alemania). Junto con un grupo de especialistas en la obra de Goethe, en este lugar Steiner colaboró en la publicación de una compilación de trabajos conocidos y también inéditos de este icono de la literatura alemana. Asimismo, cuando había cumplido los veinticinco años Steiner alcanzó cierta sistematización de su pensamiento y publicó sus dos primeros libros: Teoría gnoseológica de la concepción goetheana del mundo (1886) y Filosofía de la libertad (1894). Estas dos obras son en la actualidad consideradas los pilares básicos de todo su pensamiento posterior.

En los últimos años del siglo XIX, Steiner desempeñó su labor como coeditor de la revista Magazin fur Literatur. Uno de los artículos que presentó en esta publicación motivó que fuera invitado a participar en los círculos teosóficos ${ }^{1}$. Desde ese momento, el autor de Filosofía de la libertad empezaría a ofrecer ciclos de conferencias sobre temas de naturaleza esotérica, llegando a convertirse en el secretario de la Sección Alemana de la Sociedad Teosófica. Su participación en ella finalizó en 1913, momento en el 
que Steiner decidió fundar la Sociedad Antroposófica con 2.500 miembros y cuya presencia mundial desde entonces ha ido en aumento.

La recién creada Sociedad Antroposófica sería el espacio en el que los nuevos miembros continuarían encontrándose regularmente con el objetivo de seguir profundizando en una concepción espiritual de la existencia. En el seno de esta nueva organización se emprenderían proyectos tan emblemáticos para la antroposofía como la construcción del primer Goetheanum².

Es importante mencionar que en aquel tiempo uno de los miembros más destacados de la sociedad antroposófica era Emil Molt, director de la fábrica de cigarrillos Waldorf-Astoria. Un personaje crucial para la historia de la pedagogía Waldorf. Como director de la fábrica, Molt creó un programa innovador de clases de adultos que supliera la carencia de formación que había detectado en los trabajadores de la empresa tabacalera. No obstante, parece ser que pese a la buena acogida inicial de estos programas, muchos trabajadores sintieron que estos habían llegado tarde, lo que llevó al propio Molt a concebir que la oportunidad de recibir formación era más pertinente en etapas tempranas. Así fue cómo Molt decidió proponer a Steiner la creación de una escuela, con el objetivo de que este asumiera la planificación y su dirección pedagógica (Molt, 1991: 138). Steiner aceptó y en agosto de 1919 formó al primer cuerpo de maestros. Un mes más tarde, la primera experiencia de la pedagogía Waldorf empezó.

Según lo expuesto hasta el momento, resulta importante señalar que toda aproximación al pensamiento antroposófico y sus aportaciones a la pedagogía ha de quedar vinculada inexorablemente a la biografía intelectual de Steiner. Pues es en la vida de un pensador tan singular como Steiner y en la particular relación de conceptos que establece en su obra, en donde se encuentran los orígenes de este movimiento pedagógico. Un movimiento que ha sido ampliamente desarrollado por quienes han venido trabajando en la pedagogía Waldorf después de la muerte de Steiner en 1925.

En líneas generales, se podría decir que la antroposofía es la ciencia espiritual fundada por Rudolf Steiner a principios del siglo XX que tiene por centro y punto de apoyo al ser humano (Lanz, 2000: 11). De ahí que como versa en la cita más célebre y repetida de Steiner: «[la antroposofía] es un sendero de conocimiento que pretende conducir lo espiritual en el ser humano a lo espiritual del universo» (Easton, 1980: 359). Con todo, aunque el punto de partida es la visión material, anímica y espiritual del hombre, la antroposofía también es un camino de conocimiento en aras de conseguir elevados estados de conciencia partiendo de despertar facultades y órganos que duermen en todo ser humano (Steiner, 1996: 15). Siendo este un aspecto de relevancia axial en la pedagogía Waldorf.

\section{La educación de naturaleza antroposófica y el jardín de infancia Waldorf}

La educación de naturaleza antoposófica responde a un conjunto de categorías y conceptos de carácter particular que fueron desarrolladas, en su mayoría, por Rudolf Steiner. Muchas de estas categorías pueden resultar extrañas para quienes no hayan tenido un acercamiento teórico previo a la antroposofía; no obstante, su análisis resulta de gran importancia para una aproximación teórica al juego y su relación con la educación dentro de este modelo pedagógico. Para su análisis se toma como referencia alguno de los textos en los que el pensamiento de Steiner en relación con la educación quedó más nítidamente expuesto.

En este sentido, la conferencia «La educación del niño a la luz de la antroposofía», que Steiner pronunció en 1907, es, sin duda, el germen 
La pedagogía Waldorf y el juego en el jardín de infancia. Una propuesta teórica singular

de todo su pensamiento educativo. En este texto se encuentran algunas indicaciones sobre las peculiaridades evolutivas del niño en cada etapa vital, así como las nociones educativas que deben responder a su desarrollo. Si bien, no fue hasta 1919, como consecuencia de la creación de la primera escuela Waldorf anteriormente mencionada y por la necesidad detectada de formar maestros para aquel proyecto, cuando Steiner profundizó y detalló la educación de orientación antroposófica.

Según Steiner, el verdadero fundamento de la educación y también de la enseñanza deben basarse en el conocimiento de las leyes que presiden el desarrollo de los seres humanos (Steiner, 1907: 12). Son estas leyes de naturaleza espiritual las que se encuentran en la base de la didáctica y el currículum de la pedagogía Waldorf. Baste mencionar que una de las peculiaridades más sobresalientes es la que hace referencia a la evolución que vive el alma humana. Así, según Steiner las cualidades anímicas cambian a medida que los niños crecen, correspondiendo a la educación adaptarse al ritmo que marcan estas cualidades, ya que según señaló Steiner toda pedagogía debe tener en cuenta que son las fuerzas del alma las que afectan al organismo físico (1981b: 18).

De esta forma, para Steiner la educación de orientación antroposófica debía tomar en consideración que la estructura de la biografía humana se dividía en septenios. El fundamento de esta estructura tiene su razón de ser en «el tiempo que emplean los distintos cuerpos sutiles del ser humano en su correspondiente maduración» ${ }^{3}$ (Crottogini, 1997: 31). Como consecuencia, la educación debía organizarse en tres etapas: de los 0 a los 7 , de los 7 a los 14 y de los 14 a los 21. En el primer septenio la cualidad anímica predominante es el querer o la voluntad, en el segundo el sentir y en el tercero el pensar.

Los septenios son la base conceptual de la educación de naturaleza antroposófica. Comenzando por el análisis del primero de ellos, en la conferencia «La educación del niño desde el punto de vista de la antroposofía» Steiner plantea del siguiente modo sus características principales:

«... hasta la aparición de los nuevos dientes, alrededor de los siete años, el cuerpo humano tiene que llevar a término sobre sí mismo una tarea sustancialmente distinta de las de todas las demás épocas de su vida: los órganos físicos tienen que amoldarse a ciertas formas: sus condiciones estructurales han de recibir determinada orientación y tendencia» (Steiner, 1907: 15).

Así pues, según la antroposofía es el cuerpo etéreo $^{4}$ el que lleva a cabo la función de dar forma a los órganos físicos dentro del primer septenio. Para ello las palabras «imitación» y «ejemplo» son la clave para la pedagogía Waldorf en esta etapa. Y es que se considera que al imitar todo lo que acontece a su alrededor, los órganos físicos del niño están estructurando sus propias formas. Tanto es así que en este septenio Steiner considera que «el niño es todo órgano sensorio» (1924: 59). O lo que es lo mismo, las percepciones que recibe el niño de su entorno las integra sin poder todavía discriminar.

Todo esto explica, a grandes rasgos, la importancia que se otorga al concepto de imitación en el jardín de infancia Waldorf. Y es que dentro de la pedagogía antroposófica adquiere un significado relevante en los siete primeros años del educando tanto el ambiente físico por sus peculiaridades estéticas, como la figura del educador por la influencia directa que ejerce sobre la formación física del niño. Asimismo, el jardín de infancia se concibe como un lugar en el que se desarrollan actividades diversas que tienen sentido para los niños. En este espacio se aprende haciendo, por eso se alternan momentos de juego libre con la realización de manualidades de muy diversos tipos: pintura con acuarela, modelaje con cera de abeja o elaboración de pan.

El segundo septenio comienza a partir de los siete años de edad y queda marcado por la

Bordón 65 (I), 2013, 79-92, ISSN: 0210-5934・83 
irrupción de la segunda dentición. Este acontecimiento es interpretado por la antroposofía como el signo visible del momento en el que las fuerzas etéreas han terminado su función plasmadora en el cuerpo, haciéndose a partir de entonces más anímico-espirituales. Sobre esta idea Steiner escribe: «Desprendidas ahora de lo corpóreo, [las fuerzas etéreas] actúan sobre el sistema respiratorio-circulatorio, hecho que se puede observar en el fenómeno de que a esa edad se fortalece el ritmo de la respiración y el pulso de la circulación» (Steiner, 2004: 144).

Pedagógicamente, este cambio fisiológico propio del segundo septenio abre la posibilidad para que el adulto enseñe unos contenidos que le permitan despertar el sentir de los niños. Es el momento de perseguir en cada actividad pedagógica una «implicación de los sentimientos del niño, buscando una intensa identificación personal con el tema que se toque» (Rawson y Richter, 2000: 30). La cualidad anímica del sentir que predomina en esta etapa hace que se incluyan contenidos escolares donde abundan imágenes e historias, así como el propio concepto de ritmo tan característico de la pedagogía Waldorf.

Por último, a los catorce años comienza el tercer septenio. En esta etapa nace el cuerpo astral, también llamado sensitivo o de la conciencia. Una caracterización muy adecuada de este tercer septenio la aportan Martyn Rawson y Tobias Richter en el libro The Educational Tasks and Content of the Steiner Waldorf Curriculum, un texto de referencia obligada para los maestros de las escuelas que siguen el pensamiento de Steiner:

«Los sentimientos eran la fuente de la vida interior del niño, pero a partir de ahora [del tercer septenio] adquieren un nuevo nivel de independencia. La vida interior de un individuo se coteja con el mundo exterior en una relación que aún ha de encontrar su forma. Entre otros aspectos esta relación es creada por la capacidad de formarse juicios. El contenido de todas las clases debería responder a esa necesidad, apelando a esa capacidad y ofreciendo un contexto donde el individuo pueda desarrollar sus facultades. Eso quiere decir que la tarea de la educación es proporcionar oportunidades de aprendizaje donde se pueda experimentar y hacer conscientes leyes objetivas que sean accesibles al pensamiento» (Rawson y Richter, 2000: 77).

Centrándonos en el primer septenio, que comprende el jardín de infancia según Steiner, es el hogar el espacio cultural que mejor se adapta a lo que los niños requieren en este periodo. Esto explica que el aula, en esta propuesta educativa, sea concebida como una prolongación del hogar por su estructuración pedagógica y estética. En cierto modo podría decirse que en esta pedagogía se valoran los aspectos tradicionales del cuidado de la infancia, considerando que espacios como el hogar ejercen la sana estimulación que a esta edad se necesita.

Tomando como referencia los principios pedagógicos expuestos por Steiner, en los jardines de infancia Waldorf los niños de 3 a 6 años están juntos en el mismo aula. Con este tipo de organización se procura generar un ambiente propicio para experiencias e intercambios. Por un lado los mayores tienen que cuidar y respetar a los pequeños, los cuales, a su vez, imitan a los mayores y desarrollan la espera y la paciencia ante las actividades que ellos aún no pueden hacer.

Asimismo, el jardín se organiza en función de actividades que suponen una experiencia directa para los niños. Como ya hemos señalado, en términos de la pedagogía Waldorf se considera que los medios idóneos para aprender son la imitación y el ejemplo. Dichas actividades tienen un ritmo y un sentido antroposófico que también fueron expuestos por Steiner en el ciclo de conferencia anteriormente mencionado: «La misión de la educación, espiritualmente concebida, consiste en concordar el espíritu anímico con el 'cuerpo biológico', entre los que hay que establecer la armonía y la consonancia» (1981a: 5). 
La pedagogía Waldorf y el juego en el jardín de infancia. Una propuesta teórica singular

La búsqueda de la armonía entre el espíritu anímico y el cuerpo biológico explica el lugar especial que en el modelo educativo antroposófico y su concepción del juego tiene la función de la respiración adquirida por el ser humano al nacer. De acuerdo con este modelo, la jornada escolar se encuentra organizada de tal forma que permite dar cabida a múltiples actividades, que se estructuran tomando como referencia un concepto singular de respiración. Así, las actividades que se llevan a cabo en un jardín de infancia Waldorf quedan divididas a partir de dos categorías centrales que articulan el fundamento teórico de esta pedagogía. Estas categorías son, por una parte, la contracción, categoría que abarca a las actividades que poseen un objetivo mínimamente definido y acotado en el tiempo ${ }^{5}$ y, por otra, la expansión, principio teórico que aporta un componente de libertad que abre y redefine constantemente la propia actividad del niño. Ambas categorías, en última instancia, responden a la relevancia mencionada que el proceso de respiración y los momentos de inspiración y espiración, respectivamente, tienen en la pedagogía Waldorf. Es dentro de esta segunda categoría de expansión donde se ubica el tiempo y el espacio propicio del juego libre.

\section{El juego en la pedagogía Waldorf a partir de la selección de seis características principales}

Una vez expuestos los momentos esenciales de la biografía intelectual de Rudolf Steiner y los fundamentos teóricos principales de la pedagogía antroposófica, es momento de analizar el modo en que estos elementos se integran en la concepción del juego dentro del modelo educativo Waldorf. El reto que se plantea es seleccionar un conjunto de características propias del juego en esta pedagogía que no solo ayuden a quienes realizan su primer acercamiento a esta propuesta, sino que también aporten una hoja de ruta teórica para quienes en la práctica siguen este modelo. En este sentido, seis son las características principales seleccionadas que definen el juego en la pedagogía Waldorf y que serán desarrolladas con detenimiento en este epígrafe: proporciona el tiempo y el espacio para la consolidación de una serie de hitos evolutivos claves en la pedagogía Waldorf; está estrechamente vinculado con la naturaleza imitativa del niño; como actividad de expansión se ubica en momentos que favorecen la respiración del niño; los objetos que se utilizan están hechos con materiales naturales y poseen una gran versatilidad; excluye por definición elementos intelectuales de sus objetivos; $y$, por último, está estrechamente vinculado con el desarrollo espiritual tan característico de la propuesta educativa antroposófica.

\section{Los hitos evolutivos}

Todo acercamiento teórico al juego dentro de la pedagogía Waldorf debe partir de la consideración que la antroposofía hace de las especificidades propias de la maduración del niño en el primer septenio. En este sentido, el papel relevante que se otorga al jardín de infancia parte, según palabras del propio Steiner, de que «la condición humana del niño en sus primeros siete años es radicalmente distinta de la de la vida posterior» (Steiner, 1923: 14). La importancia de estos primeros años radica en que el niño alcanza en este tiempo tres hitos evolutivos: andar, hablar y pensar. Hitos inigualables en relevancia a cualquier otro del desarrollo posterior de todo ser humano.

La primera de esas conquistas que los niños hacen en este periodo es la acción de andar, que es la base para la consecución del equilibrio espacial necesario en relación con el mundo físico. Como producto de esta acción en la que interviene todo el organismo motor, a su vez, nace el habla, lo que es interpretado por la antroposofía como la traducción de los movimientos externos en movimientos internos que generan el lenguaje. Ello lleva a un posterior momento en el que el habla trasciende el simple 
nombrar cosas, siendo entonces cuando el niño empieza a formar frases y aparecen los primeros rudimentos del pensamiento ${ }^{6}$. Y es precisamente esta perspectiva teórica de la evolución madurativa la que otorga una relevancia destacada al juego libre. Pues el juego es un elemento clave que favorece tanto la maduración como el desarrollo sensorio-motor que el niño ha de conquistar durante los primeros siete años de su vida.

\section{La naturaleza imitativa del niño}

Para comprender la importancia que la pedagogía Waldorf otorga a la naturaleza imitativa del niño en su concepción teórica del juego, una premisa básica del primer septenio detectada por Steiner es que «la actividad desarrollada por los niños en el jardín de infancia debería consistir única y exclusivamente en la imagen externa de lo que las personas mayores hacen» (en Jaffre, 2004: 17). De esta manera, en un día cualquiera de un jardín de infancia Waldorf se puede observar cómo los maestros siempre están desarrollando una actividad en presencia de los niños. El objetivo, en última instancia, es imitar las acciones que corresponden a la figura materna y paterna en el hogar familiar.

Este papel destacado que posee la naturaleza imitativa del niño en la actividad lúdica queda, asimismo, manifiesto en las palabras de Almon cuando señala que gracias al desarrollo de esta capacidad «se activa en el niño su necesidad natural para ver el trabajo real desarrollado por los adultos» (2004: 6). Y es que es precisamente esta copia de lo que llevan a cabo los adultos, enriquecida, a su vez, con la imaginación de los niños, la que se integra intencionalmente en el juego. Baste mencionar que para la antroposofía dicha actividad tiene una influencia directa en el desarrollo físico de los niños en este primer septenio. Según menciona el propio Steiner, con esta acción imaginativa llevada a cabo en el juego se posibilita «una movilidad interior en los órganos, movilidad que determinará su forma correcta» (1907: 17).

\section{La respiración}

Ya se ha mencionado el papel crucial que el concepto de respiración posee en la estructuración de la jornada escolar del jardín de infancia Waldorf. De hecho, es dentro de una de las categorías centrales que se derivan de este concepto, es decir, de la expansión, que deviene, a su vez, de la espiración, donde el juego encuentra su lugar y su momento. Así, algo característico del juego en un jardín de infancia Waldorf es que los niños juegan libremente alternando el aula con otros espacios como el arenero, el jardín, los columpios y otro tipo de estructuras y elementos de recreo habilitados para este nivel educativo. De este modo, como actividad de expansión, se da inicio al juego estratégicamente en determinados momentos del día para ofrecer dicho tiempo de espiración. Lo cual es fundamental para alcanzar un equilibrio con momentos de mayor concentración, o lo que es lo mismo, de inspiración.

\section{Los objetos}

Aunque en el jardín de infancia Waldorf no hay juego reglado organizado por el adulto, sino que el juego es siempre libre, para su desarrollo sí que existen unos materiales específicos. Estos objetos son elaborados a base de elementos y formas naturales. Entre los elementos predomina la madera, pues el principio pedagógico que inspira el tipo de materiales que rodean al niño se basa en ofrecer una experiencia directa de la realidad física del mundo, tomando elementos propios de la naturaleza. Respecto a las formas de los objetos Alice Jansen señala:

«Encontramos que las formas rígidas y geométricas de los típicos bloques tienen un efecto cristalizador en la imaginación y ofrecen pocas posibilidades para la construcción. Por otro lado, las curvas más o menos fluidas y los colores claros de nuestros bloques sugieren infinitas posibilidades y estimulan la imaginación hasta altas cotas de creatividad» (1955: 56). 
La pedagogía Waldorf y el juego en el jardín de infancia. Una propuesta teórica singular

No obstante, la atención que presta la pedagogía Waldorf a los objetos que se utilizan en el juego libre no se limita a los materiales y sus formas. También existe una preocupación evidente en relación con los límites que conllevan juguetes excesivamente detallados para la experiencia lúdica. Así, los juguetes son sencillos y apenas poseen características que los definan; siendo en todo momento más valorados por la versatilidad que ofrecen para estimular el desarrollo de la fantasía e imaginación de los niños. Los elementos que siempre se pueden encontrar en las aulas de infantil Waldorf son cocinas, cunas, carros de bebé, caballos para mecerse, telas, muñecos y disfraces, así como espacios con troncos, piñas, castañas, conchas, animales de lana y fieltro, instrumentos musicales y cuentos, entre otros.

\section{Los elementos intelectuales}

Un hecho que determina el fundamento teórico del juego que se desarrolla en los jardines de infancia Waldorf es que la pedagogía antroposófica espera al segundo septenio para incluir elementos intelectuales en la educación. Esta es una característica que marca una distancia notable con respecto a los modelos pedagógicos que actualmente predominan en los sistemas educativos oficiales, pues los niños en las escuelas Waldorf tienen tiempo para el juego libre sin que este quede determinado por pretensiones intelectuales del mundo adulto. Si bien, esta situación de alejamiento respecto a ciertas ambiciones intelectuales lejos de diluir el rol que corresponde al juego en la pedagogía antroposófica, lo termina por ubicar en un lugar protagonista de toda su propuesta educativa.

Como consecuencia, el papel que corresponde al cuerpo en el proceso educativo de los niños en el jardín de infancia encuentra diferencias sustanciales respecto a los enfoques que han predominado tradicionalmente en la pedagogía. Para la antroposofía, como señaló Steiner, si se fuerzan las capacidades intelectuales del niño, se detiene su desarrollo corporal (1923: 30). En este sentido, es interesante señalar que Steiner al marginar la formación intelectual en los primeros siete años de vida de los seres humanos, no solo estaba dando fundamento a su original propuesta pedagógica, sino que, al tiempo, estaba presentando una importante crítica al enfoque educativo y antropológico que regía uno de los modelos en auge por excelencia de la educación infantil a principios del siglo XX: el kindergarten froebeliano.

Para Steiner la importancia de no introducir elementos intelectuales en el juego infantil se observa, en su mayor expresión, al constatar que incluso los mismos materiales utilizados en la actividad lúdica debían mantenerse alejados de toda posible intervención intelectual adulta que los pervirtiera. Esta intervención, en última instancia, limita una de las principales vías instintivas de aprendizaje de los seres humanos a esta edad temprana, esto es, la ya referida imitación. Y esto era algo que el propio Steiner consideraba que lo distanciaba respecto a lo propuesto por pedagogos como Froebel. Sucedía que el afamado educador alemán no había considerado en su profundidad las limitaciones teóricas que posteriormente inspiraron al movimiento de la Escuela Nueva, las cuales eran notorias para la antroposofía. Situación que expresó Steiner en los siguientes términos:

«Los jardines de infancia desarrollados por Froebel y otros inspirados por un amor verdadero hacia los niños no se han dado cuenta de que la imitación es una parte muy importante de la naturaleza del niño, quienes sólo pueden imitar lo que no se ha impregnado de una cualidad intelectual. Por ello, no debemos introducir en el jardín de infancia formas elaboradas artesanalmente que han sido ingeniosamente 'pensadas'» (Steiner, en Jaffre, 2004: 17).

\section{La espiritualidad}

Las cinco características expuestas hasta el momento en este apartado se encuentran inpregnadas $y$, al tiempo, determinadas transversalmente 
por el peso que la formación del espíritu posee dentro del modelo pedagógico Waldorf. El espíritu, de tal forma, es concebido como una necesidad capital potencial a desarrollar dentro de la antroposofía y también, pues no podía ser de otra forma, el eje teórico que vertebra la conceptualización del juego de toda la educación antroposófica.

Desde esta perspectiva, se considera que las fuerzas etéreas responsables de la plasmación de las formas físicas en los primeros años de la vida están presentes de un modo más importante durante este primer septenio que en el resto de la existencia. Y es que la antroposofía considera que para la formación de los órganos físicos y su correcto desarrollo es necesario dar espacio al ejercicio de una voluntad sana que se arraiga en dichos órganos, y que encuentra su máxima expresión en el juego libre. Citando de nuevo a Steiner:

«Lo que ganamos con el juego entre el nacimiento y el cambio de dientes, lo que los niños experimentan en un estado de ensoñación, son fuerzas de una espiritualidad que todavía no ha nacido del ser humano, que todavía no ha sido absorbida, o mejor dicho reabsorbida, en el cuerpo humano» (Steiner, 2004: 23).

Una perspectiva que, sin duda, otorga una trascendencia de gran calado al juego libre en el proceso educativo de los niños. Una conceptualización, además, que bien puede complementarse con las palabras de Grohman en relación a esta actividad: «El juego es seriedad, porque en el juego está el espíritu. Jugando, el niño ejercita su espiritualidad» (2005: 253). De ahí que prestar una atención constante al juego libre del niño sea de gran importancia para la pedagogía Waldorf, puesto que representa una imagen de su ser y porque la individualidad que manifiesta el educando en el juego sirve de sustento a etapas posteriores de su vida. $Y$ es que el modo en que se ha trabajado la actividad lúdica durante la infancia encuentra su reflejo en el inicio del cuarto septenio. Según las palabras de
Steiner: «El juego de los niños hasta los siete años entra en el cuerpo a la edad de los 21-22, cuando ganamos independencia en nuestro entendimiento y la habilidad de juzgar las experiencias» (en Jaffre, 2004: 24).

\section{Conclusiones}

El juego es un elemento central de la propuesta pedagógica antroposófica, siendo este un aspecto que no puede pasar desapercibido en cualquier aproximación teórica al modelo educativo que inspira a las escuelas Waldorf. Así, para la antroposofía toda la educación infantil se organiza y vertebra en torno al juego. Baste mencionar que la vida espiritual, epicentro del pensamiento desarrollado por Rudolf Steiner, encuentra en el juego un elemento clave inigualable en su potencialidad para el desarrollo de las capacidades innatas de los seres humanos.

No es el juego, por tanto, un elemento más del proceso educativo en una escuela infantil Waldorf, lo que explica la especial atención que se le otorga en el primer septenio. Como ya ha sido mencionado, es en estos años en los que el niño debe llevar a cabo una tarea distinta de las que desempeñará en el resto de épocas a lo largo de su vida. Pues es un tiempo en el que los órganos físicos se amoldan a ciertas formas, lo que demanda una orientación que sus condiciones estructurales naturales han de recibir. De aquí la importancia que la pedagogía de Steiner otorga a la respiración, pues esta abre la posibilidad de acompasar de forma armónica el desarrollo del niño en sintonía con la organización del tiempo y el espacio propios de cada jornada escolar.

Esta perspectiva original del juego presente en la pedagogía Waldorf es, sin duda, un desafío para quienes desde la teoría de la educación buscan analizar su fundamento. De ahí que en este trabajo se hayan seleccionado seis características que definen al juego en los primeros siete años de vida del niño. Seis características 
La pedagogía Waldorf y el juego en el jardín de infancia. Una propuesta teórica singular

generales que pueden ayudar a dar continuidad a otros estudios que detecten en esta concepción de la pedagogía, así como en el pensamiento de Steiner, una posible línea de investigación de cara al futuro. Además, quienes desempeñan su labor en escuelas infantiles, tanto si pertenecen al movimiento Waldorf como si no, pueden inspirar su práctica al acercarse a los principios teóricos que sostienen el juego y que han quedado presentados en este texto.

No obstante, un problema evidente del modelo educativo Waldorf es que se sirve de conceptos sumamente particulares que apenas guardan relación con la terminología vigente en otras áreas de las ciencias sociales, y en especial de la pedagogía. Así, todo acercamiento al mundo antroposófico exige un estudio del pensamiento de un autor como Steiner cuyos principios filosóficos, en gran medida, dejan muchas puertas abiertas para la libre interpretación. Esta particularidad dificulta no solamente la comprensión de los pilares teóricos que sostienen esta alternativa pedagógica, sino también la expansión de muchas de las valiosas propuestas que residen en el interior de esta conceptualización tan singular de la educación. Y es que la confusión, la falta de unidad interpretativa, la escasez de criterios consensuados o la tergiversación interesada de algunos postulados esgrimidos por Steiner, en ocasiones, se ha colado en las aulas de las escuelas Waldorf, lo que ha generado escisiones entre distintos proyectos que en su día dieron inicio compartiendo un mismo ideal pedagógico.

El mundo académico, en este sentido, tampoco ha contribuido con una detallada interpretación de las aportaciones pedagógicas de la antroposofía en relación al juego. La mayoría de trabajos que han pretendido aproximarse desde el campo de conocimiento de la pedagogía al modelo educativo Waldorf han sido elaborados por investigadores afines a la antroposofía o que directamente participan de esa propuesta pedagógica. Se observa necesario, por tanto, una visión crítica que dé respuesta a los desafíos que presentan los cambios de paradigmas que están teniendo lugar en el contexto de la teoría de la educación. Una visión, en definitiva, que cuestione aspectos fundamentales del pensamiento de Steiner, al tiempo que rescate lo que esta propuesta puede aportar.

Con todo, todavía hoy para la pedagogía, la teoría del juego y su relación con la educación y la infancia desarrollada por el movimiento de la Escuela Nueva, y en especial por Froebel, es el principal referente. Fenómeno que se hace evidente al observar la tendencia unidireccional predominante por integrar el juego en la educación infantil, sin cuestionar el fundamento y el sentido de dicha integración. Lo que ha limitado el potencial propio de la actividad lúdica, al tiempo que ha marginado otras posibles alternativas que no han compartido este principio teórico. Siendo este el caso de la pedagogía Waldorf y su búsqueda de una inclusión de la educación en el juego y no al contrario. Una perspectiva teórica de la actividad lúdica que supone un giro conceptual radical y que no guarda semejanza con otras corrientes teóricas de la pedagogía contemporánea. Pues para la antroposofía el juego es parte intrínseca del ser humano, mientras que la educación es un elemento externo siempre al servicio del libre desarrollo de cada individuo, con especial énfasis en los primeros siete años de vida.

\section{Referencias bibliográficas}

BuRKHARD, G. (2000). Buscando el hilo de la vida. Madrid: Editorial Rudolf Steiner.

Cabrera Acosta, M. A. (2005). La crisis de la modernidad y la renovación de los estudios históricos. En Ferrar Lorenzo (ed.) (2005), Repensar la historia de la educación. Nuevos desafios, nuevas propuestas. Madrid: Biblioteca Nueva. 
Crottogini, R. (1997). La tierra como escuela. La biografía humana: proyección terrena de un acontecer cósmico. Argentina: Editorial antroposófica.

EAston, S. C. (1980). Rudolf Steiner: herald of a new epoch. New York: Anthroposophic Press.

Gabert, E. (1966). Emil Molt: The Waldorf-Astoria Cigarrette Factory: The Waldorf School Association: The World School Association, en R. SteIner, Conferences with the teachers of the Waldorf School in Stuttgart. 1919-1920. London: Steiner Schools Fellowship Publications, 7-11.

Grohmann, G. (2005). Aforismo, en BerLín, J. (recopilador): El primer septenio. La educación preescolar según Rudolf Steiner. Buenos Aires: Editorial Antroposófica, 253.

JAFFRE, F. (2004). On the play of child. Indications by Rudolf Steiner for working with young children. New York: Waldorf Early Childhood Association of North America.

JAnsen, A. (1955). The kindergarten in the Rudolf Steiner school, en R. Pusch, Waldorf schools. New York: Anthroposophic Press, volumen 1, 55-62.

LANG, P. (2004). The kindergarten child, The Research Institute for Waldorf Education. Research Bulletin, IX, 2, 13-16.

Lanz, R. (2000). Antroposofía. Nociones básicas. Buenos Aires: Editorial antroposófica.

Molt, E. (1991). Emil Molt and the beginnings of the Waldorf School Movement. Autobiographical sketches. Edinburgh: Floris Books.

OldFIELD, L. (2001). Free to learn. Introducing Steiner Waldorf Early Childhood Education. United Kingdom: Hawthorn Press.

PomÉs, J. (2006). Diálogo Oriente-Occidente en la España de finales del siglo XIX. El primer teosofismo español (1888-1907): un movimiento religioso heterodoxo bien integrado en los movimientos sociales de su época, Revista HMiC: Història moderna i contemporània, 4, 55-74.

Rawson, M. y Richter, T (2000). The Educational Tasks and Content of the Steiner Waldorf Curriculum. London: Steiner Waldorf Schools Fellowship.

RorTy, R. (1990). La historiografía de la filosofía: cuatro géneros, en R. RoRTy, J. B. ScHNEEWIND y Q. SKInner (comp.), La filosofía de la historia. Ensayos de historiografía de la filosofía. Barcelona: Paidós.

Steiner, R. (1923). Andar, hablar y pensar, en Berlín, J. (rec.) (2005), El primer septenio. La educación preescolar según Rudolf Steiner. Buenos Aires: Editorial.

Steiner, R. (1981a). El estudio del hombre como base para la pedagogía. México D.F.: Editorial Waldorf.

STEINER, R. (1981b). The renewal of education through the science of the spirit. London: Steiner Waldorf Schools Fellowship.

STEINER, R. (1907). La educación del niño desde el punto de vista de la antroposofía, en R. STEINER (1997), La educación del niño. Metodología de enseñanza. Madrid: Editorial Rudolf Steiner, 7-49.

STEINER, R. (1924). Metodología de la enseñanza y las condiciones vitales de la educación. Ciclo de cinco conferencias pronunciadas en Stuttgart. Primera conferencia, en R. STEINER (1997), La educación del niño. Metodología de enseñanza. Madrid: Editorial Rudolf Steiner, 51-67.

STEINER, R. (1996). Cómo conocer los mundos superiores. Madrid: Editorial Rudolf Steiner.

Steiner, R. (1997). El curso de mi vida. Buenos Aires: Epidauro.

STEINER, R. (2004). El segundo septenio. Fundamentos pedagógicos para el saludable desarrollo del ser humano. Buenos Aires: Editorial antroposófica.

WAlser, R, (2011). Jakob Von Gunten. Madrid: Siruela. 
La pedagogía Waldorf y el juego en el jardín de infancia. Una propuesta teórica singular

\section{Notas}

${ }^{1}$ La teosofía fue un movimiento iniciado por la ocultista rusa Helena Petrovna Blavatsky y el coronel estadounidense Henri Steele Olcott en 1875 en la ciudad de Nueva York. Siguiendo a Pomés, la teosofía consistió en un nuevo humanismo internacional que pretendía la complementariedad de razón y espiritualidad buscando la instauración de unos valores universales; no se trataba de una nueva religión, más bien intentaba ser una síntesis entre religión, filosofía, ciencias y psicología (2006: 55-57). La participación de Rudolf Steiner en los círculos teosóficos según narra en su biografía, se debió a que en ese momento solo encontró en ellos un público receptivo para la integración de los impulsos del mundo espiritual en la vida (1997: 262), objetivo que Steiner planteó en los inicios de su obra y desarrolló durante su trayectoria vital.

2 Pensado en un primer momento para albergar las crecientes representaciones teatrales, especialmente los Dramas-Misterio de Rudolf Steiner, el Goetheanum se convirtió en un edificio para el fomento de la vida espiritual de la incipiente comunidad antroposófica. Más información en www.goetheanum.org.

${ }^{3}$ Los cuerpos sutiles son también los denominados miembros constitutivos del ser humano: cuerpo físico, cuerpo de vida o etérico, cuerpo astral y el Yo.

${ }^{4}$ Según la antroposofía, el cuerpo etéreo o morfogenético es una envoltura con la que nacemos y que en los primeros siete años de vida se dedica a configurar nuestras formas físicas, es decir, actúa a nivel físico y en el segundo septenio, a nivel anímico. Este cuerpo etéreo ha sido también denominado como fuerza vital o élan vital por el filósofo francés Henri Bergson, coetáneo de Rudolf Steiner.

${ }^{5}$ Algunos ejemplos de actividades de contracción presentes diariamente en la jornada escolar son: los corros, el momento del desayuno, la realización de manualidades y la narración del cuento.

${ }^{6}$ Para un desarrollo más exhaustivo, se puede consultar: KöNIG, K. (2004): The first three years of the child. Walking, speaking, thinking. Edinburgh: Floris Books.

\section{Abstract}

\section{Waldorf education and play in the kindergarden: An outstanding theoretical proposal}

The aim of this article is to analyze the theoretical conception of play in Waldorf schools with particular emphasis on early childhood education and its relationship with play-oriented activities. It provides a brief profile of Rudolf Steiner, and a summary of the relevant theoretical principles of Waldorf education. The analysis is framed by critical historiography in relation to intellectual history. The main contribution of this article resides in the identification of six defining characteristics of play in an anthroposophical education. These are: the capacity to contribute to the consolidation of evolutionary milestones; the connection with the imitative nature of the child; the placement of play in such a way that it favours healthy breathing; the use of versatile and natural materials; the exclusion of intellectual components in the educational objectives; and, finally, its relationship with the spiritual development of children. As a result, the article concludes that the novelty that Waldorf bring to the educational debate on play, childhood, and education is the need to integrate education to play rather than play to education.

Key words: Play, Waldorf education, Anthroposophy, Rudolf Steiner, Spirituality. 
Patricia Quiroga Uceda y Jon Igelmo Zaldívar

\section{Résumé}

\section{La Pédagogie Waldorf et le jeu à la maternelle: Une proposition théorique exceptionnelle}

Le but de cet article est d'analyser la conception théorique du jeu dans les écoles Waldorf en portant une attention particulière à l'éducation de la petite enfance et sa relation aux activités ludiques. L'article offre un bref profil de Rudolf Steiner et un résumé des principes théoriques les plus pertinents de la pédagogie Waldorf. L'analyse est présentée dans le cadre de l'historiographie critique en lien avec l'histoire intellectuelle. La principale contribution de cet article consiste dans l'identification de six caractéristiques distinctives du jeu dans une pédagogie anthroposophique. Ces caractéristiques sont: la capacité du jeu de contribuer à consolider les jalons de l'évolution, le lien avec la nature imitative de l'enfant; la localisation du jeu de manière à favoriser la saine respiration; l'usage de matériaux versatiles et naturels; l'exclusion d'éléments intellectuels parmi les objectifs éducatifs; et finalement la relation avec le développement spirituel des enfants. À cause de cela, l'article conclut que la nouveauté que Waldorf apporte au débat éducatif sur le jeu, l'enfance et l'éducation est la nécessité d'intégrer l'éducation au jeu plutôt que le jeu à l'éducation.

Mots clés: Jeu, Pédagogie Waldorf, Anthroposophie, Rudolf Steiner, Spiritualité.

\section{Perfil profesional de los autores}

\section{Patricia Quiroga Uceda}

Becaria predoctoral del programa de Formación del Profesorado Universitario de la Universidad Complutense de Madrid (UCM), en el Departamento de Teoría e Historia de la Educación. Miembro del Grupo de Investigación sobre Cultura Cívica y Políticas Educativas. Ha sido investigadora visitante en el Early Childhood Research Centre del Froebel College de University of Roehampton (Londres). Entre sus líneas de investigación destacan la educación en valores y ciudadanía y propuestas educativas de carácter alternativo, como la pedagogía Waldorf.

Correo electrónico de contacto: pquiroga@edu.ucm.es

\section{Jon Igelmo Zaldívar}

Profesor colaborador de la Universidad de Deusto. Doctor en Educación por la Universidad Complutense de Madrid. Investigador posdoctoral del Grupo de Investigación sobre Cultura Cívica y Políticas Educativas de la UCM. Entre sus líneas de investigación cabe destacar las teorías críticas con la escuela de los años sesenta y setenta, el pensamiento de Ivan Illich y las corrientes contemporáneas de la historiografía de la educación. Ha realizado estancias de investigación en el Centro de Estudios Sociológicos de El Colegio de México (México DF) y en la Faculty of Education de Queen's University (Kingston, Canadá), donde actualmente es becario postdoctoral.

Correo electrónico de contacto: jigelmoza@deusto.es 